\title{
Stakeholder Understanding of Corporate Social Responsibility (CSR) in Emerging Markets with a Focus on Middle East, Africa (MEA) and Asia
}

\section{A Study of Stakeholders to Assist Multinational Corporations in Understanding Regional Requirements for Operating in Emerging Markets}

\author{
Virginia Munro \\ Published online: 18 May 2013 \\ (c) CEEUN 2013
}

\begin{abstract}
Limited consensus in society on the definition of corporate social responsibility (CSR) still exists; and the finding that stakeholders may not understand what CSR entails is also of concern. Stakeholders across the emerging markets of Middle East and Africa (MEA), from three multi-national companies comprised of four nationality groups (MENA, Asian, Western expatriate and Sub-Sahara), are asked questions relative to the "components" of the definition of CSR (economic, legal, ethical and philanthropic) provided by Carroll (Acad Manag Rev 4(4):497-505, 1979) and Leisinger (Bus Soc Rev 112(3):316-342, 2007) and more recently, Melo and Garrido-Morgado (CSR Environ Manag 19(1):11-31, 2012). Overall, findings suggest a broader and more contemporary definition be utilised and communicated back to stakeholders to increase understanding of company specific CSR strategy. Significant differences were found across nationality groups in the MEA region, suggesting a need to incorporate cultural differences and the perceptions of different nationality groups in CSR planning. Recommendations for CSR strategy in emerging markets such as MEA are made, and are discussed in light of religious beliefs, culture and country of origin.
\end{abstract}

Keywords CSR - Stakeholders · Emerging markets - Middle East and Africa $(\mathrm{MEA}) \cdot$ Asia $\cdot$ Culture and Nationalities

\footnotetext{
V. Munro ( $\square)$

Middlesex University, London, UK

e-mail: munro.coms@gmail.com

V. Munro

Middlesex University, Dubai, UAE

V. Munro

De Montfort University, Leicester, UK
} 


\section{Literature Review}

\section{An Unclear Definition}

It is acknowledged that the lack of consensus on a definition of corporate social responsibility (CSR) will impact long-term on research in the field of CSR (Bartlett and Devin, cited in Ihlen et al. 2011, p 61). Part of the difficulty is that CSR is an intangible and elusive term (Smith and Langford 2009) and can mean "anything to anybody" (Jamali 2008) and responsible behaviour towards stakeholders is not at the same level for all (Yelk1kalan and Köse 2012). This is further complicated by the contextual nature of CSR, which is influenced by the (external) environment an organization operates within (Azmat and Samaratunge 2009), and the internal environment of the organization itself (Mehrdost 2012; Brammer et al. 2007a; Rayton 2006). The 'unclearness' is further embedded in the 'institution' of CSRits specialists, journals, conferences, discussions, academic teaching and research (Crane et al. 2008). Dahlsrud (2008) has in fact found over 37 different definitions while other researchers explore whether the term CSR should actually exist (Kitzmueller and Shimshack 2012). The majority of researchers however report that CSR is a: growing phenomenon; buzzword; philosophy; a relationship of business and society over time (Jan and Baloch 2011; Tripathy and Rath 2011). With so many perspectives, pragmatists and visionaries, CSR has become the perfect battleground (Strategic Direction 2011).

\section{The Historical Evolution of CSR}

There is a long history developing the concept of CSR (Krumwiede et al. 2012) resulting in hundreds of concepts and definitions referring to a similar theme (Van Marrewijk 2003). The debate gained momentum in the 30s, followed by the Bowen definition (1953): "businesses have the obligation to pursue those (CSR) policies, to make those decisions, or to follow those lines of action which are desirable in terms of the objectives and values of our society" (p 6). Businesses believing in the "public good," emphasize different elements (or "components") of the definition (Blowfield and Murray 2008). Starbucks talks about "listening to customers," Coke "gives back" a litre of water, the European Commission emphasises "interacting with stakeholders on a voluntary basis," while Rio Tinto makes a commitment to "improve the quality of life for the: work force; their families; local community; and society" (p 13).

Following Bowen, Carroll (1979) identifies four categories (or "components"): economic; legal; ethical; and philanthropic. Economic, legal and ethical responsibilities are mandatory in many developed countries. In contrast, philanthropic activities in developed and developing countries are not mandatory. Such activities however can greatly influence a stakeholder's opinion of a company and their products (Brown and Dacin 1997). Leisinger (2007), for example, places philanthropic activities at the top of his "corporate pyramid," as the "can" dimension, listing legal and regulatory as a "must" dimension and going beyond legal norms as an "ought to" dimension. Philanthropy is placed amongst 
"discretionary" business responsibilities (i.e. a voluntary decision of management). More recently, Melo and Garrido-Morgado (2012) have embodied a five dimensional construct: employee relations; diversity issues; product issues; community relations; and environmental issues. This is consistent with GRI guidelines for reporting CSR. Performance indicators are listed under economic, environmental and social categories. The 'social' category is further divided into labour, human rights and product responsibility, expanding more recently to include human rights, local community and gender, and will be expanded further in 2013 (Global Reporting Initiatives (GRI) 2012).

These additional "components" need to be added to the original definitions penned by Carroll (1979), Leisinger (2007), and Melo and Garrido-Morgado (2012). Components such as: looking after the stakeholder and maintaining CSR throughout the supply chain need to also be considered. These newer "components" of the CSR definition are explored in the current paper.

\section{Stakeholder Definitions and "Components" of CSR}

If the stakeholder is confused with the definition of CSR (Boulstridge and Carrigan 2000), this may be due to a lack of understanding for traditional business responsibilities (governance, ethical and legal) as opposed to the social issues and philanthropic and charitable acts, more often mentioned in popular media. Lack of understanding may also be because CSR means different things to different stakeholders. Some see CSR as a way to maximize profits, government stakeholders see it as a legislative requirement to ensure safe products and workplaces, and consumers define CSR as high quality for good price, referring to ethical or philanthropic aspects in varying degrees (Smith and Langford 2009). To the community; employees; and society at large-the definition is even more varied.

Within a company, the internal CSR definition can also vary across company divisions (accounting, law, governance, marketing, IT, human resources and so on) depending which "component" of the CSR definition is involved in the company's overall CSR strategy.

Academic research continues to report the importance of examining CSR from a stakeholder 'understanding and perception' approach. For example, Okpara and Wynn (2012), in their recent study have shown that stakeholder perceptions can influence management's decision to respond in an encouraging manner to CSR initiatives, while also incorporating balanced guidelines for social responsibility strategies that add value to stakeholders (Fernández 2011). It is questionable however as to whether the definition of CSR has been actually put forward for scrutiny by the stakeholder (Maignan 2001), and therefore the value of CSR as perceived by the stakeholder, remains uncertain, alongside recent research requests to keep abreast of stakeholder expectations, understanding and awareness of CSR (Brønn 2012).

\section{Regional and Global CSR Differences}

Many companies define CSR by their activities. This delivers it's own complexities as a single company may have different activities in different geographic regions. 
Some researchers would therefore disagree with this approach. As engaging in CSR is becoming an increasingly common business practice globally and across industries (Yong et al. 2012) this is an important issue to address. Hence, while CSR has gained popularity in the past decade globally, there are still differences in commitment at a regional level to consider (Lim and Tsutsui 2012).

Popoli (2012) for example, states CSR strategy of a global corporate or brand cannot be accomplished by a differentiated approach but requires an integrated CSR strategy that does not change in the various countries where the company operates (p 419). Confirming that a "one solution fits all" definition for CSR should be adapted to the: development; awareness; and ambition levels of organizations in different regions, is supported by Van Marrewijk (2003).

A current academic literature review on CSR reveals a recent focus on 'differences' across geographical regions and countries at different stages of development. Freeman and Hasnaoui (2011) for example, examined CSR across four nations (UK, France, USA and Canada) and concurred with the findings of national and international bodies and previous research, that "both within and among countries, there exists no clear definition (or understanding) of the concept of CSR" (Freeman and Hasnaoui 2011, p 419). These results echo past research. Maignan (2001), for example, found differences in CSR definitions across French, German and American regions. French and German respondents rated 'economic' activities as less important than American, and listed 'socially responsible' organisations on their shopping list, more often than Americans. In addition, Singh et al. (2008) who examined Spanish and UK respondents found the former to be more critical in valuing information on 'ethical' and 'environmental' practices, however their interest in these variables was small. Lack of awareness of CSR in Spain was cited as a factor. Spain is also on the back foot in the line up of countries in the European Union (EU) and is therefore currently seen as less developed than some of the other EU countries.

Podnar and Golob (2007) examined stakeholder CSR expectations in Australasia and found individuals expect companies to be business responsible and comply with 'ethical-philanthropic' expectations and be sensitive to different 'cultural' expectations. Ramasamy and Yeung (2009) who looked at similar indices to (Maignan 2001) found Chinese (from Shanghai) and Hong Kong respondents much more supportive of CSR when shopping, emphasising 'ethics,' rather than 'economics,' in their definition, concluding that perceptions of business responsibility varies across 'cultures'.

Research in BRIC (Brazil, Russia, India, China) countries has also found significant differences between countries (Ardichvili et al. 2012). These findings are consistent with results in emerging markets. Arli and Lasmono (2010), for example, examined consumer perception in the developing country of Indonesia and found consumers still unaware of CSR and as a result, unwilling to support it and unable to distinguish between the different "components" of CSR. Azmat and Zutshi (2012) also refer to differences between developed and developing economies in their emphasis of the different components of CSR, where 'social issues' were given more priority. Their conclusion from this is that in developing countries social issues are given more political, economic and media emphasis than environmental, 
ethical or stakeholder issues. Visser (2008) also found a stronger emphasis on philanthropic traditions focused on community development in developing countries and suggested that CSR perspectives within a country are strongly related to the economic, social, political condition of that country.

Different regions also have various nationalities and/or 'origins' that citizens and expatriates are originally from. This is particularly the case for the region of this study. Asians are a large part of the workforce in developing regions such as MENA, where both Asian and Western expatriates, make up $80 \%$ of the population in the United Arab Emirates (UAE), (Ronnegard 2010). This is important to note as Hamilton et al. (2008) found immigrant entrepreneurs adjust their beliefs, values and norms to acclimatize to the host country they are living in, but at the same time maintain their links with their traditional culture. It may therefore be important that multinational companies (MNCs) understand stakeholders in this light, when selecting CSR strategy relevant to the host countries they operate within and the expatriates they employ. Research by Campbell et al. (2012) reveals this is not always the case, finding that "foreign affiliates from more distant home countries are in fact less likely to engage in host-country CSR" (p 84).

A similar regional argument can be used for corporate governance. Wong (2008), for example, states that there is an emerging convergence towards best-practice standards for corporate governance, and that there is also recognition that no single model of governance can exist. Similar to reports for CSR in the East, he argues that the prevailing legal and institutional forms in Asia mitigate against effective governance systems and practices, suggesting that cultural, historical and institutional contexts are critical factors in developing better and more effective practices (p 149). The same argument can be utilised for the other CSR "components".

\section{Different Demographics, Culture and Religion across MEA Regions}

Demographically, young people in the MENA region make up the highest proportion of the population (Washington Post 2011). One in five people in the MENA region are defined as "youth": those aged 15-24 (Assaad and Roudi-Fahimi 2007). The UAE within the MENA region, records $45 \%$ of its population below the age of 15 (The National Human Resource Development \& Employment Authority 2005). Generally in the Gulf, youth numbers are high. $61 \%$ of Saudi Arabia is under the age of 25, for example (Khan 2007).

Employees (internal stakeholders) are also particularly important in this region. Gulf countries during the current boom, have found it difficult to attract and retain employees with the right skills (Ronnegard 2012). Taking into account the perspectives of internal stakeholders in this region is very important.

Culture is also important in understanding CSR. 'Social-cultural' and 'ethicallegal' approaches have a fundamental role in the promotion of CSR and the social responsibilities understood by organizations (Mehrdost 2012). 'Culture' is also one of the most important variables influencing 'ethical' decision-making (Rawwas et al. 2005) and can influence levels of CSR activity, reporting and disclosure. Culture governs how individuals perceive their responsibilities, and is recognised as a determinant of business practice and ethical values (Hofstede 1980; Rizk 2008). 
It is also interesting to note that the region has deep roots in its indigenous Bedouin 'culture' and traditional mantra, "attending to your people" (Soubra 2006; Ronnegard 2010). This has come down through the generations and still exists in the national psyche of the region.

Acknowledgment of 'culture' is particularly important in regions where religion and culture are strongly intertwined and upheld, such as the Middle East. The principle of Zakat (local giving and "gifting") is of great importance: and a predominate aspect of the Quran and one of the five pillars of Islamic religion. Defined as a 'wealth tax', Zakat comprises compulsory charitable giving for designated groups, supporting the weaker members of society (Brammer et al. 2007b).

In Islamic thought, individuals and organisations are expected to feel socially responsible for others in the community (Rizk 2008, p 209). According to The Universal Foundation (2012), the faith of Islam prescribes charity and goodwill towards all mankind and encourages helping those less fortunate, emphasising the welfare of the community over individual rights. Zakat is collected and spent for the "good of society" (Rizk 2008, p 209). Researchers suggest that religious values permeate Gulf countries far more than the West (Ronnegard 2012), and with the tradition of "gifting" (Zakat) being very prominent in Islamic societies, this has a particular influence on the shape of CSR in the region. Authors working in the region confirm that Zakat is utilised as a form of corporate donation generally to a charity organization or needy individuals and is most forthcoming during the holy fasting month of Ramadan (Islamcan 2012; Zorzopulos 2006). Therefore, not only do Muslims give their time to Allah at Ramadan, with fasting and prayer, they also give of their material goods (Vanguard 2012).

Anecdotal evidence reported by Ronnegard (2010), from the UAE, suggests that the concept of CSR is understood by local businessmen as a corporate form of Zakat (p 10), making CSR synonymous with corporate philanthropy. Philanthropy and charitable giving is common across organisations from Middle Eastern countries, as a part of a CSR programme or as an individual activity (corporate citizenship) for societal improvement (Khan 2007). Hence, "gifting" is done at a personal and individual level, and seen as a personal duty and a corporate one (Guermat et al. 2003). This must have a strong influence on stakeholder perceptions of this within the MEA and MENA regions.

Differences in understanding of CSR between regions, may also be a result of a country or region employing different business roles/principles within their corporations, dependent on the underlying business genre of the country they operate within (Azmat and Zutshi 2012; Matten and Moon 2008; Visser 2008). The majority of studies on CSR are still embedded in the economic, cultural and organizational context of the West (Arevalo and Aravind 2011). A focus on the East must therefore be considered, plus the developing nations and emerging markets of these regions. It must be acknowledged that a "one size fits all" CSR systems based on Western codes and regulations should not necessarily be implemented in the East, or in developing countries or emerging markets (Peters et al. 2011).

There is an increasing number of Western and MNCs leaving their footprint in developing countries and emerging economies. Their CSR philosophies, beliefs and 
understanding-must therefore be examined within these regions. The role of the $\mathrm{MNC}$ in emerging markets however has only recently begun to attract the attention of academic researchers and management theorists (Reimann et al. 2012). MNCs moving into emerging economies however need to deal with a variety of nationalities they may not be familiar with and also expatriates from various countries living in developing regions.

This paper adds to the current academic body of CSR literature by focusing on MNCs in a mix of emerging and frontier markets and developing countries in the MEA region, and examines the perspectives of stakeholders comprised of the many nationalities and cultures living and working within this region.

\section{Research Gaps}

To contribute to the CSR discipline and industry globally, contemporary research needs to include analysis of the more recent CSR "components" of the CSR definition and mix as outlined by the Global Reporting Initiatives (GRI) (2012) guidelines, including looking after stakeholders and CSR throughout the supply chain. Newer "components" of the CSR definition, such as these, have not been examined directly in this format before. Additional questions regarding the respondents self-rated understanding of CSR and the importance they attach to companies practising CSR has also been added to the current study. These issues have not been directly examined together before. In addition, the majority of CSR research in general has been conducted amongst 'customers' as a random selection of the general public. In the past 'internal' stakeholders (employees) are not asked questions traditionally asked of customers (and 'external' stakeholders), and vice versa. The current study asks employees questions traditionally asked of customers and vice versa.

On the occasion when issues have been examined amongst 'employees' it has been limited to one industry sector at a time, such as banking and/or insurance (for example, Gabriel and Regnard 2011; Maignan 2001; Ramasamy and Yeung 2009). The current study includes MNCs from three different sectors (accounting, law and IT), as opposed to one or two sectors. In addition, there is little mention to date, of the individual nationalities included in each research sample. The current study for the first time, tests multiple nationalities under four broad nationality groups typical of the MEA region (MENA, Asian, Western expatriates and Sub-Sahara).

Finally, generic CSR research to date has primarily been conducted in developed markets: Europe and North America, and more recently BRIC, Hong Kong and China for emerging markets, but has not yet been contemplated fully across the Middle East and Africa (MEA) region. There is a demand to examine MNCs in emerging markets (Peters et al. 2011; Reimann et al. 2012), such as MENA and MEA

\section{Research Questions and Hypotheses}

Based on the findings from the literature review above the following research questions have been formulated: 
1. It is expected that stakeholders will not understand completely what CSR is?

2. It is expected that stakeholders will not understand completely the different "components" of CSR, which defines what CSR is and that different nationalities will not emphasise different components of CSR.

3. If stakeholders do or do not understand what CSR is, it is expected this will influence the level of importance they attach to CSR.

\section{Research Methodology}

\section{Questionnaire Design}

Questions are comprised of fixed choice questions for frequency measures and Likert scales rated from one to five (where 1 is least important or preferred and 5 is most important or preferred). Demographic questions, requiring verbatim answers and a variety of answers, were converted into numerical codes. For recording of nationalities and office locations, respondents listed: their nationality as listed on their passport; and the geographic region of the office where they are located.

Questions were designed especially for the current study, exempting the CSR "components" question which was adapted from Maignan (2001) and Maignan and Ferrell (2001), of which Ramasamy and Yeung (2009) also utilised in part. Questions from their studies ask respondents if businesses need to be, ethical, abide by legal reporting and support philanthropic activities, for example, in a series of contextual statements. The current study adapts these questions to ask respondents which terms they associate more or less with CSR. For example, where Maignan (2001) and Maignan and Ferrell (2001) ask: Should businesses be committed to well-defined ethics principles? The current study asks: How much do you associate CSR with ethical ways of conducting business? (see "Appendix").

In their questionnaires, Maignan (2001), Maignan and Ferrell (2001) and Ramasamy and Yeung (2009), utilised the main categories of the definitions for Carroll (1979) and Leisinger (2007): economic, legal, ethical, philanthropic, employees, social, community. The current study adds to this: looking after and reporting to the stakeholder; and CSR in business lines throughout the supply chain.

\section{Data Collection and Quantitative Analysis}

Quantitative analysis was chosen above qualitative analysis due to the need to cover large geographic distances of the MEA region under the umbrella of one study. All respondents gave their informed consent to participate and remained anonymous. Respondents were given a 'self-completed' questionnaire and instructed to answer all questions anonymously and in one sitting to make responses valid. Independent 2 sample $t$ test analysis was utilised to determine whether the means of nationality groups differed statistically from each other. As an initial study, this is 'exploratory' in nature, to allow for further analysis and an ongoing longitudinal study. 


\section{Research Results and Analysis of Findings}

Demographics

\section{Nationality}

Findings correspond to $\mathrm{N}=251$ respondents across four nationality groups (MENA, Asians, Sub-Sahara Africa and Western Expatriates) from three sectors, information technology $(\mathrm{N}=40)$, accountancy $(\mathrm{N}=163)$ and law $(\mathrm{N}=48)$, based throughout MEA. The findings for nationality groups, are of particular interest and is the focus of the current paper (Fig. 1).

Respondents from 11 nationality groups were divided into 4 main nationality groups typical of the region, with the frequencies for each group as follows:

1. $\mathrm{N}=60$, Western expatriates $=(24 \%)$

2. $\mathrm{N}=50$, Asian $=(20 \%)$

3. $\mathrm{N}=122$, Middle East and North Africa (MENA) $=(49 \%)$

4. $\mathrm{N}=15$, Sub-Sahara Africa $(\mathrm{SSA})=(6 \%)$

$(\mathrm{N}=4$ not stated)

Regarding the location of offices and respondents, UAE has the highest proportion of respondents $(\mathrm{N}=91)$, followed by Lebanon $(\mathrm{N}=46)$, Saudi Arabia $(\mathrm{N}=22)$, Kuwait $(\mathrm{N}=14)$, Turkey $(\mathrm{N}=10)$, Oman and Bahrain each with $\mathrm{N}=9$, and South Africa with $\mathrm{N}=8$. The remaining countries with just one or two offices (and/or employees) are Egypt, Nigeria, Kenya, Algeria, Jordan, Qatar and Morocco.

\section{OVERALL NATIONALITY GROUPS ACROSS THREE \\ SECTORS \\ $(\mathrm{N}=\mathbf{2 5 1})$}

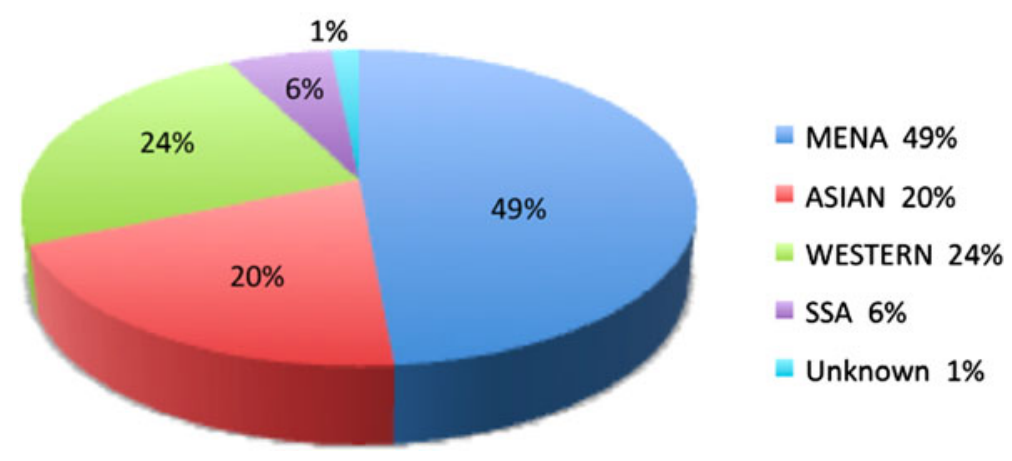

Fig. 1 Overall Nationality Groups Across Three Sectors $(\mathrm{N}=251)$ 


\section{Emerging and Frontier Market Countries}

As reported above, the majority of respondents are from the Middle East, North Africa (MENA) region (49\%). The World Bank (2012) lists the countries of MENA as: Bahrain, Egypt, Jordan, Algeria, Kuwait, Lebanon, Morocco, Oman, Qatar, Saudi Arabia, Tunisia and the UAE. A smaller number of countries from the Sub-Sahara region (South Africa, Nigeria and Kenya) are also included in the study. MENA is considered a developing region, alongside Sub-Sahara Africa (The World Bank 2012).

All countries in the current study are listed in the developing region, and many of them are listed as either an emerging market or frontier market (World Bank 2010). In the MENA region, all countries are listed as frontier markets except for Egypt and Morocco, which are listed as emerging markets (MSCI 2012). Turkey and South Africa (as part of the Sub-Saharan sample) is listed by the FTSE as advanced emerging markets (FTSE 2012).

The respondent breakdown of numbers into nationalities is typical of the MENA region, with $28 \%$ being Asian, and originally from the developing regions of Asia, in particular India and Pakistan, or they are first or second generation MENA with parents and grandparents originally from Asia. The FTSE (2012) lists Pakistan as a frontier market, alongside countries such as Kenya and Nigeria, and India is listed as an emerging market. $24 \%$ of the sample are Western expatriates and are from developed countries.

\section{Age and Education}

The overall age of participants across sample is 21-29 years (42\%) and 30-39 years (42\%) with just $14 \%$ aged 40-49 years and $2 \%$ aged $60+$ years. Similar age groupings can be found for nationalities in Table 1 below. MENA has the largest proportion across sample (52\%) for the younger age group (21-29 years), with a combined $88 \%$ when including the second youngest sample category (30-39 years). The Western sample has the largest proportion (70 \%) in the middle age range from 30-39 (48\%) and 40-49 (22\%). The majority of the sample is University educated with $49 \%$ graduates, $39 \%$ postgraduates, $1 \% \mathrm{PhDs}$ and $11 \%$ with high school qualifications comprising the administrative sample.

Table 1 Age

\begin{tabular}{|c|c|c|c|c|c|}
\hline Age & $21-29$ & $30-39$ & $40-49$ & $50-59$ & Total \\
\hline Westerners & 14 & 29 & 13 & 4 & 60 \\
\hline Asian & 23 & 24 & 3 & 0 & 50 \\
\hline MENA & 63 & 44 & 14 & 1 & 122 \\
\hline SSA & 3 & 6 & 5 & 1 & 15 \\
\hline Total N & 103 & 103 & 35 & 6 & 247 \\
\hline
\end{tabular}

No answer $=4$ 
Table 2 Gender Range Across Nationalities

No answer $=4$

\begin{tabular}{lccr}
\hline Gender & Male & Female & Total \\
\hline Westerners & 26 & 34 & 60 \\
Asian & 28 & 22 & 50 \\
MENA & 67 & 55 & 122 \\
SSA & 10 & 5 & 15 \\
Total N & 131 & 116 & 247 \\
\hline
\end{tabular}

\section{Gender across Nationalities}

Gender across sample is $\mathrm{N}=133(53 \%)$ males and $\mathrm{N}=118(47 \%)$ females, with a $6 \%$ difference. These weightings are similar for each nationality group, however Westerners have slightly more females $\mathrm{N}=34(56 \%)$ than males $\mathrm{N}=34(43 \%)$. (Table 2).

\section{Understanding CSR}

In a Likert rating scale from understanding completely to not understanding, $46 \%$ $(\mathrm{N}=115)$ of respondents rated themselves as having average understanding followed by $27 \%(\mathrm{~N}=67)$ understanding a lot, and $11 \%(\mathrm{~N}=27)$ understanding completely with only $1 \%$ not understanding CSR.

Across nationalities, SSA $(\bar{X}=3.6)$ are more likely on average to have greater understanding of CSR followed by Western expatriates, Asian $(\bar{X}=3.4)$ and MENA $(\bar{X}=3.1)$ samples. Independent $t$ test analysis shows a statistical difference between Western and MENA $(p<0.05)$ and MENA and SSA $(p<0.01)$ for understanding of CSR. In both cases, MENA respondents believe they have less understanding and SSA greatest understanding overall. Given the small sample size for SSA $(\mathrm{N}=15)$, SSA results are considered, but not discussed at length in this paper.

\section{"Components" of CSR}

Key words on the horizontal axis in Fig. 2 relate to each component (or category) associated with the definition of CSR. Key terms (italicised in the questionnaire), are abbreviated and explained in the key below. In general, respondents rated CSR being associated with community, social, philanthropy/charity and environment high and legal, stakeholder and supply chain less high, however they are all above a neutral score, exempting supply chain. Across nationalities, supply chain was also rated low with the Asian sample showing higher ratings for emissions and employee.

When examining the modes for these scores, all four nationalities strongly associate the top four "components" listed above for overall findings, however Westerners were most likely to rate employees neutral and MENA and Asian nationalities did not strongly associate legal as a component of CSR.

Independent $t$ test analysis reveals there are significant differences across nationalities. The Asian sample is statistically more likely to associate employees 


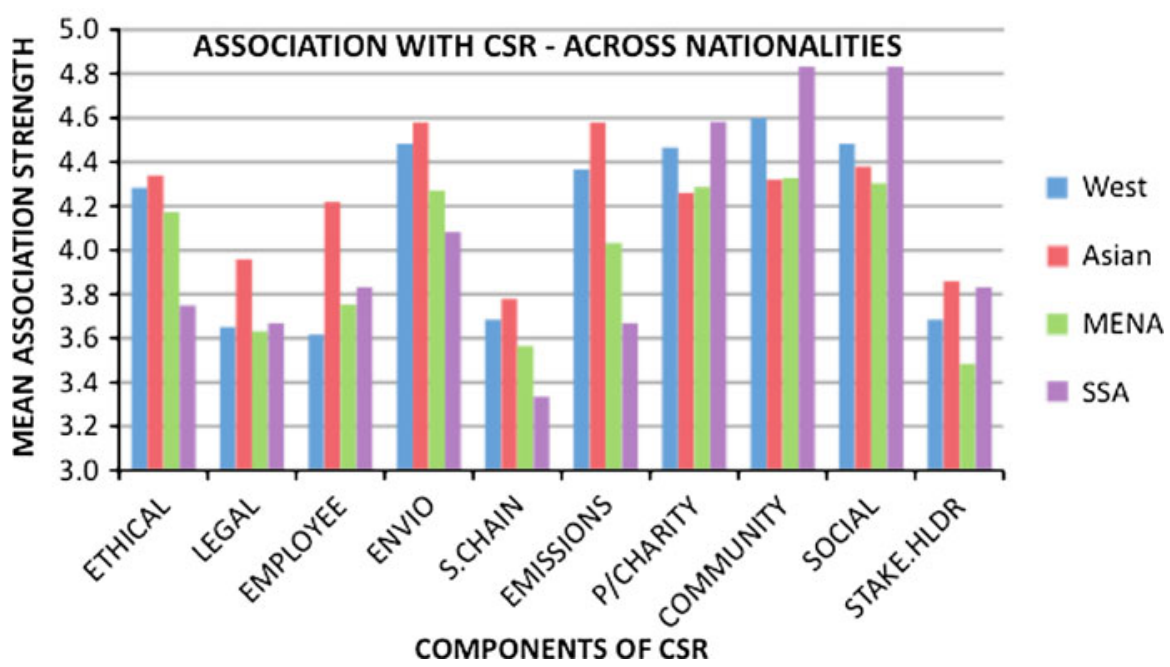

Fig. 2 Association with CSR Across Nationalities (average ratings). ENVIO environment, S.CHAIN supply chain, P/CHARITY philanthropic and charity, STAKE.HLDER stakeholder

$(\mathrm{p}<0.01)$ than Western and MENA. Westerners and Asians were more likely to associate emissions $(\mathrm{p}<0.05)$ with CSR than MENA. The Asian sample was statistically more likely when compared with MENA to associate CSR with the environment $(\mathrm{p}<0.05)$ and Western respondents were less likely to associate employee and Asian are more likely to associate supply chain, environment and employee, than all other groups.

Importance of CSR

Across sample, $51 \%(\mathrm{~N}=128)$ of respondents rated CSR as extremely important, $44 \%(\mathrm{~N}=112)$ as reasonably important, and only $3 \%(\mathrm{~N}=7)$ as average importance and $1 \%(\mathrm{~N}=2)$ stating it somewhat important.

SSA and MENA on average felt companies practising CSR was extremely important $(\bar{X}=4.53, \bar{X}=4.50$ respectively), followed by Asian and Western samples that felt it was of reasonable importance $(\bar{X}=4.34, \bar{X}=4.32$ respectively), Independent $t$ test analysis revealed no significant differences across nationalities or sectors, suggesting that nationalities across the board in MEA feel CSR is quite important.

\section{Conclusion and Recommendations}

$84 \%$ of respondents state a combined average and above average understanding. These results therefore do not support Boulstridge and Carrigan (2000). It is clear from the current findings that these particular stakeholders do understand what CSR is. However, just under half the sample (46\%), say they have only 'average' 
understanding. There is therefore room for improvement in understanding CSR. The MENA nationality group, states they have significantly less understanding than other nationality groups residing in the region. Educational themes should therefore be included in CSR strategy in MENA and include: What CSR is-as part of a corporate's overall CSR strategy.

As respondents rated all "components" above neutral for association with CSR (exempting supply chain), this indicates they understand CSR enough to recognise the different aspects of CSR. Respondents were more likely to rate high, the more recent "components" of the original Carroll (1979) CSR definition. Social, community, emissions and environment rated relatively high agreeing more with Leisinger's (2007) “corporate pyramid" placing-community, social and philanthropy (on the top tier) —and regulations, emissions and profits (on lower tiers). This also fits better with the five dimensional definition of Melo and Garrido-Morgado (2012), which focuses on employee relations, diversity issues, community relations, product issues and environmental. There is also a strong focus on social, which relates to the research by Arli and Lasmono (2010) in developing regions.

The newer and emerging "components" of CSR in this study, not listed in the original definitions of CSR - supply chain and looking after the stakeholder-are less associated with CSR. By way of educating stakeholders, an MNC's CSR strategy needs to refer to these components, with an explanation as to why this is a part of their strategy and underlying core business.

The findings of the current study would support, that with reasonable stakeholder understanding, stakeholders do not specifically list economic and ethical components as more important than philanthropic, as Arli and Lasmono (2010) found (for Indonesian respondents with limited understanding of CSR), and Spanish respondents, with comparatively less understanding of CSR (Singh et al. 2008).

Similar to the findings of various researchers, differences across countries exist in the current study (Ardichvili et al. 2012; Arli and Lasmono 2010; Azmat and Zutshi 2012; Maignan and Ralston 2002; Ramasamy and Yeung 2009; Podnar and Golob 2007; Visser 2008). For the more traditional components of CSR, such as ethics and legal, they are less associated with CSR in the MEA region in comparison to similar studies from developed regions. In contrast, other components such as environmental, social and community, are rated with higher association to CSR in the MEA region compared to other regions. Hence, even though respondents of the MEA region state they have quite good understanding of CSR, they rated ethical, and in particular legal, with less importance than other components typical of the traditional definition of CSR. The lack of emphasis on ethics and legal, confirms the suggestion by Brown and Dacin (1997) that economic, legal and ethical responsibilities are mandatory in developed countries as opposed to developing economies.

The current study suggests a lack understanding of the more corporate responsibilities of a business, such as governance, ethical and legal as opposed to the more social areas related to philanthropic and community. These findings are consistent with the research of Maignan (2001). In contrast, Ramasamy and Yeung (2009) found that China (Shanghai) and Hong Kong respondents, emphasised 'ethics,' rather than 'economics,' in their definition. This would make sense, 
because the Middle East is considered to be a series of frontier markets (The World Bank 2012), i.e. a pre-emerging market. They may therefore be less aware of CSR as a concept than stakeholders in emerging and developed markets.

This finding may also be due to cultural sensitivity issues, first relayed by Podnar and Golob (2007) in the Australasian region. Taking into account the religious principles in relation to Zakat ("gifting"), and the indigenous Bedouin culture of "attending to your people" first, this may confirm why this region is more likely to emphasize social, local and community over ethical, legal and economic components. Relatively low ratings for supply chain confirms that stakeholders in the region do not understand that a company's CSR is immersed throughout internal and external services-from product production to end of line. Hence, although these stakeholders believe they understand what CSR is-there is room to educate further on the newer "components" of CSR. It is also an opportunity to educate stakeholders on what an MNC does-how CSR is incorporated throughout their organization and therefore the community-via the supply chain and industry surrounding them.

Respondents rating supply chain as less associated with CSR may also confirm Blowfield and Murray's (2008) findings that businesses emphasise (and exclude) different elements of CSR. How businesses explain their CSR is how stakeholders and society gather knowledge of it. Companies should therefore define their own version of CSR - as part of their CSR strategy-and outline the different "components" of CSR throughout their organization's supply links. Looking after the stakeholder also rated comparatively low. This may reflect that as "employees" this group of respondents, may not feel valued as part of their corporation's CSR or that the MNC does not associate CSR strongly with its stakeholders. Some respondents are originally from regions where employee or stakeholder rights are less valued culturally, such as some parts of Asia. With $60 \%$ of the population in the UAE being Asian or Western expatriates (Ronnegard 2012), this is an extremely interesting finding for this region and needs to be examined further.

The findings confirm there are differences across nationalities. Asian respondents rated employees, emissions and environment statistically higher than MENA and Westerners, and Asians rated emissions statistically higher than MENA - indicating that emissions and environment need to be more closely associated with the definition of CSR in this region. These "components" need to be highlighted in CSR campaigns and targeted in CSR messaging for the significantly large Asian and MENA customer base and workforce in MEA.

The response for the Asian sample in the current study is also consistent with the findings of Hamilton et al. (2008) and Azmat and Zutshi (2012), for their respective host country and immigrant Asian respondents, who were found to adjust their beliefs, values and norms to acclimatize to the host country but at the same time maintain their links with their traditional culture. The majority of the Asian population living and working in the MEA region originally come from emerging economies, with overcrowded cities, pollution and outpourings of emissions. Asians also tend to come from emerging markets, which does not necessarily respect human rights (such as child labour and educating women). As many of the respondents in the current study are Asian or first generation MEA, and therefore 
born in the region, they may give more significance to local issues, than western expatriates for example (and to issues impacting on the countries that they or their families are originally from).

Research by Campbell et al. (2012) reveals that "foreign affiliates from more distant home countries are in fact less likely to engage in host-country CSR" (p 84). This may account for the lower rated responses from Western expatriates working in the region, who are often employed only for a short time in the host country of the $\mathrm{MNC}$ and therefore have less long-term interest and/or commitment.

With regards to the different nationality groups in this study, SSA and MENA tended to rate CSR as more important than Western and Asian expatriate groups living in the MEA region. This may again be due to traditional cultural principles and religious beliefs associated with corporate and personal "gifting" (Zakat) in the MEA region and in particular MENA and the UAE, where the principle of Zakat is integral to society. This needs to be examined further throughout the region.

The findings confirm the importance and inclusion of indigenous culture and religious principles in regional CSR strategy, such as Zakat, and the tradition of "giving" locally and looking after their people as a part of the indigenous Bedouin culture of the region. Being from this culture and identifying with its themes, would naturally enhance an individual's perspective of the importance of these aspects of CSR. These issues need to be emphasised in CSR strategy throughout the region, and particularly the UAE and the Gulf countries of the MENA region.

\section{Summary and Future Research}

Overall, the findings of the current study support the argument that a "one size fits all" approach should not be utilised by MNCs globally. As there is an increasing number of MNCs leaving their footprint in emerging economies (Reimann et al. 2012), the current findings suggest that CSR strategy based on Western codes should not necessarily be implemented in the East or in emerging markets.

It is of significant interest to the MEA region that the MENA nationality group rate their understanding of CSR less than all other nationality groups. There is therefore room for improvement in understanding CSR within the MENA region, by embedding it in CSR strategy as a consistent educational message surrounding introduction of CSR activities to stakeholders. As the MENA nationality group overall are also younger, this needs to be tested further, to determine if age significantly alters understanding of CSR across nationalities. The large sample of youth in this study is reflective of the demographics for this region, and is therefore an important finding of the current study, as it suggests that younger age groups may need more education on CSR.

As stakeholders rated CSR understanding, importance and "components" (community, social and environmental) relatively high-there is much potential scope for MEA companies to expand their CSR strategy to include these components, whilst being sensitive to the cultural aspects, traditions and religious beliefs of the region. 
Overall these findings confirm that the MEA marketplace is different from the West and different from other emerging markets, with its own set of cultural sensitivities and traditions, confirming that different regions of the globe need to be assessed differently. This study adds to current perspectives by suggesting that understanding of CSR is enhanced by separately listing the "components" of the definition of CSR, which will in turn assist stakeholders to be more accepting of a company's CSR activities, by educating them on the 'broader' definition and therefore context of CSR. Academic research continues to report the importance of examining CSR from a stakeholder perspective, to influence management to respond to CSR initiatives (Okpara and Wynn 2012). If this is correct, the effect companies have on the world through their existence and activities, may end up being entirely influenced by what a stakeholder: understands; perceives; believes and requests.

\section{Appendix}

Which of the following terms do YOU associate with CSR? (1 least to 5 strongly associate)

- Ethical ways of conducting business

- Abiding by legal reporting and governance of the company business

- Businesses looking after their employees in the workplace

- Businesses looking after the environment

- Businesses looking after everyone involved in the supply chain-from production of products and services through to the customer at the end of the line

- Cutting down on waste and carbon emissions in the work environment

- Philanthropy/charity

- Businesses looking after the communities they live in

- Businesses being involved in social causes they care about

- Businesses reporting about their activities to stakeholders e.g.: investors, customers, employees

\section{References}

Ardichvili A, Jondle D, Kowske B, Cornachione E, Li J, Thakadipuram T (2012) Ethical cultures in large business organizations in Brazil, Russia, India, and China. J Bus Ethics 105(4):415-428

Arevalo J, Aravind D (2011) Corporate social responsibility practices in India: approach, drivers, and barriers. Corp Gov Int J Eff Board Perform 11(4):399-414

Arli D, Lasmono H (2010) Consumers' perception of CSR in a developing country. Int J Consum Stud 34:46-51

Azmat F, Samaratunge R (2009) Responsible entrepreneurship in developing countries: understanding the realities and complexities. J Bus Ethics 90:437-452

Azmat F, Zutshi A (2012) Influence of home-country and regulatory environment on CSR perceptions: the case of Sri Lankan immigrant entrepreneurs. Thunderbird Int Bus Rev 54(1):15-27

Blowfield M, Murray A (2008) Corporate responsibility—a critical introduction. Oxford University Press, Oxford 
Boulstridge E, Carrigan M (2000) Do consumers really care about corporate responsibility? Highlighting the attitude-behaviour gap. J Commun Manag 4(4):355-368

Bowen H (1953) Social responsibilities of the businessman. Harper \& Row, New York

Brammer S, Millington A, Rayton B (2007a) The contribution of corporate social responsibility to organizational commitment. Int J Hum Resour Manag 18(10):1701-1719

Brammer S, Williams G, Zinkin J (2007b) Religion and attitudes to corporate social responsibility in a large cross-country sample. J Bus Ethics 71:229-243

Brønn P (2012) Adapting the PZB service quality model to reputation risk analysis and the implications for CSR communication. J Commun Manag 16(1):77-94

Brown T, Dacin P (1997) The company and the product: corporate associations and consumer product responses. J Mark 61(January):68-84

Campbell J, Eden L, Miller S (2012) Multinationals and corporate social responsibility in host countries: does distance matter? J Int Bus Stud 43(1):84-106

Carroll A (1979) A three-dimensional conceptual model of corporate social performance. Acad Manag Rev 4(4):497-505

Crane A, McWilliams D, Matten J, Siegel D (2008) The Oxford handbook of corporate social responsibility. Oxford University Press, Oxford

Dahlsrud A (2008) How corporate social responsibility is defined: an analysis of 37 definitions, corporate social responsibility and environmental management 15:1-13

Fernández M (2011) The organizational social responsibility: stakeholders future managers. RIAF 4(4):87-101

Freeman I, Hasnaoui A (2011) The meaning of corporate social responsibility: the vision of four nations. J Bus Ethics 100(3):419-443

Gabriel P, Regnard Y (2011) RSE ou DD? ce que révèle l'emploi des termes dans les stratégies de légitimation des entreprises du secteur bancaire et assurance. Revue Sciences de Gestion 84:101-117

Hamilton R, Dana L, Benfell C (2008), Changing cultures: an international study of migrant entrepreneurs. J Enterp Cult 16(1):89-105

Hofstede G (1980) Culture's consequences: international differences in work-related values. Sage Publications, Beverly Hills

Ihlen O, Bartlett J, May S (2011) The handbook of communications and corporate social responsibility. Wiley, Sussex

Jamali D (2008) A stakeholder approach to CSR: a fresh perspective into theory and practice. J Bus Ethics 82:213-231

Jan S, Baloch QB (2011) Corporate social responsibility in Pakistan. Interdiscip J Contemp Res Bus 3(1):1309-1332

Kitzmueller M, Shimshack J (2012) Economic perspectives on corporate social responsibility. J Econ Lit 50(1):51-84

Krumwiede D, Hackert A, Tokle J, Vokurka R (2012) The practice of corporate social responsibility in different countries: a study of firms in Canada, Hungary, Italy, Lebanon, Taiwan and the United States. Int J Manag Part 2 29(1):389-402

Leisinger K (2007) Corporate philanthropy: the "Top of the Pyramid”. Bus Soc Rev 112(3):316-342

Lim A, Tsutsui K (2012) Globalization and commitment in corporate social responsibility: cross-national analyses of institutional and political-economy effects. Am Sociol Rev 77(1):69-98

Maignan I (2001) Consumers' perception of corporate social responsibility: a cross cultural perception. J Bus Ethics 30(1):57-72

Maignan I, Ferrell OC (2001) Corporate citizenship as a marketing instrument. Eur J Mark 35:457-484

Maignan I, Ralston D (2002) Corporate Social Responsibility in Europe and the U.S: Insights from Businesses' Selfpresentations J Int Bus Stud 33(3):497-514

Matten D, Moon J (2008) "Implicit" and "Explicit"' CSR: a conceptual framework for understanding CSR in Europe. Acad Manag Rev 33(2):404-424

Mehrdost H (2012) Strategies to promote social responsibility in cultural organizations. Int J Bus Soc Sc 3(6):236-242

Melo T, Garrido-Morgado A (2012) Corporate reputation: a combination of social responsibility and industry. CSR Environ Manag 19(1):11-31

Okpara J, Wynn P (2012) Stakeholders' perceptions about corporate social responsibility: implications for poverty alleviation. Thunderbird Int Bus Rev 54(1):91-103 
Peters S, Miller M, Kusyk S (2011) How relevant is corporate governance and corporate social responsibility in emerging markets? Corp Govern Int J Eff Board Perform 11(4):429-445

Podnar K, Golob U (2007) CSR expectations: the focus of corporate marketing corporate communications. Int J 12(4):326-340

Popoli P (2012) Linking CSR strategy and brand. Mark Theory 11(4):419-433

Ramasamy B, Yeung M (2009) Chinese consumers' perception of corporate social responsibility (CSR). J Bus Ethics 88:119-132

Rawwas M, Ziad S, Mine O (2005) Consumer ethics: a cross-cultural study of the ethical beliefs of Turkish and American consumers. J Bus Ethics 57(2):183

Rayton B (2006) Examining the interconnection of job satisfaction and organisational commitment: an application of the bivariate probit model. Int J Hum Resour Manag 17(1):139-154

Reimann F, Ehrgott M, Kaufmann L, Carter C (2012) Local stakeholders and local legitimacy: MNEs' social strategies in emerging economies. J Int Manag 18(1):1-17

Rizk R (2008) Islam and corporate governance. In: Aras G, Crowther D (eds) Culture and corporate governance research series: issues in corporate behaviour and sustainability, chapter 11. Social Responsibility Network, Leicester, pp 204-214

Singh J, Sanchez M, Bosque I (2008) Understanding corporate social responsibility and product perceptions in consumer markets: a cross-cultural evaluation. J Bus Ethics 80(3):597-611

Smith V, Langford P (2009) Evaluating the impact of corporate social responsibility programs on consumers. J Manag Organ 15(1):97-109

Soubra H (2006) An examination of the effects of cultural orientations and economical factors on CSR policy making in the UAE. Master Thesis, University of Strathclyde Business School

Strategic Direction (2011) Finns city service embraces fairer trading: catering body seeks more "ethically sound" products. Strateg Dir 27(10):23-25

Tripathy S, Rath N (2011) Practice of corporate social responsibility in NALCO and the perceptions of employees and the public. South Asian J Manag 18(4):44-61

Van Marrewijk M (2003) Concepts and definitions of CSR and corporate sustainability: between agency and communion. J Bus Ethics 44(2):95-105

Visser W (2008) Corporate social responsibility in developing countries. In: Crane A, McWilliams D, Matten JM, Siegel D (eds) The Oxford handbook of corporate social responsibility. Oxford University Press, Oxford, pp 473-479

Wong L (2008) Culture and corporate governance: revisiting the cultural imperative. In: Aras G, Crowther D (eds) Culture and corporate governance research series: issues in corporate behaviour and sustainability, chapter 8. Social Responsibility Network, Leicester, pp 149-177

Yelkıkalan N, Köse C (2012) The effects of the financial crisis on corporate social responsibility. Int J Bus Soc Sci 3(3):292-300

Yong S, Jin K, Sung-Hack L (2012) Communication strategies for enhancing perceived fit in the CSR sponsorship context. Int J Advert 31(1):133-146

Zorzopulos S (2006) Corporate social responsibility in the United Arab Emirates: a preliminary assessment. Dubai Ethics Resource Center, 2006

\section{Websites}

Assaad R, Roudi-Fahimi F (2007) Youth in the Middle East and North Africa: opportunity or challenge? Population Reference Bureau. http://www.prb.org/pdf07/youthinmena.pdf. Accessed Sep 2012

FTSE (2012) http://www.ftse.com/Indices/FTSE_Emerging_Markets/index.jsp. Accessed Jul 2012

Global Reporting Initiatives (GRI) (2012) https://www.globalreporting.org/reporting/latest-guidelines/ Pages/default.aspx. Accessed Jul 2012

Guermat C, Al Utaibi A, Tucker J (2003) The practice of Zakat: an empirical study for Gulf Countries. Working paper ISSN 1473-3307. http://people.exeter.ac.uk/cc371/RePEc/dpapers/DP0302.pdf. Accessed Sep 2012

Islamcan (2012) Ramadan, a month of generosity. http:/www.islamcan.com/cgi-bin/increaseiman/ htmlfiles/static/103794588514115.shtml. Accessed Sep 2012

Khan A (2007) From "Zakat" to CSR_corporate responsibility in the Middle East, Hill \& Knowlton Middle East, Corporate Reputation Watch Middle East 2007. http://blogarchive.hillandknowlton. com/blogs/ampersand/pages/corporate-social-responsibility-in-the-middle-east.aspx. Accessed Sep 2012 
MSCI (2012) http://www.msci.com/products/indices/tools/index_country_membership/frontier_markets. html. Accessed Jul 2012

Ronnegard D (2010) Corporate social responsibility \& the United Arab Emirates (http://www.lulu.com) and Sustainable Group International (http://www.sdg-int.org/uploads/csr-and-the-uae-final.pdf). Accessed Sep 2012

Ronnegard D (2012) Corporate philanthropy vs strategic CSR in the GCC, INSEA. The Abu Dhabi Centre. http://www.busmanagement.me.com. Accessed Sep 2012

The National Human Resource Development \& Employment Authority (2005) Human Resources Report, The National Human Resource Development \& Employment Authority. http://www.tanmia.ae/ tanmia/general/news.html. Accessed Sep 2012

The World Bank (2012) http://data.worldbank.org/country/. Accessed Jul 2012

The Universal Foundation (2012) http://www.universalfoundationny.org/index.php?option=com content\&view=article\&id=73: ramadan-is-about-sharing-and-giving\&catid=42:articles\&Itemid=82 Accessed Sep 2012

Vanguard (2012) Ramada Talk: the act of giving in Ramadan by Ishola Balogun. http://www. vanguardngr.com/2012/08/ramada-talk-the-act-of-giving-in-ramadan/. Accessed Sep 2012

Washington Post (2011) Youth movement. http://www.washingtonpost.com/wp-srv/special/world/ middle-east-youth-population. Accessed Sep 2012 